\title{
Diagnosis of tuberculosis meningitis by using Trc4 and Is6II o primers in Bangladesh
}

\begin{abstract}
Meningitis caused by Mycobacterium tuberculosis remains an important cause of morbidity and mortality worldwide, and presents particular challenges in terms of diagnosis and management. The prevalence of TB meningitis remains largely underestimated due to nonspecific clinical manifestation. At early stages diagnosis is largely based on microscopy and culture which are often less sensitive and time consuming. This study was aimed to evaluate the diagnostic potentials of urinary polymerase chain reaction (PCR) by using TRC4 and IS6110 primers. Further the results were also compared by culture on Lowenstein-Jensen (LJ) media and AFB smear by Zeihl-Nelson (ZN) staining. A total of 20 CSF samples were studied from clinically suspected cases of tubercular meningitis. All the samples were processed for conventional ZN staining, TB culture on LJ media and TB-PCR by IS6110 and TRC4 primers by standard protocols. Of the total 20 samples, 12 cases were diagnostically positive TB meningitis samples among which bacteriological test were positive in only $1(8.33 \%)$ cases. PCR assay detected MTb in $10(83.33 \%)$ patients by TRC4 primers and in $8(66.67 \%)$ patients by IS6110 primers. Since some strains of MTB may lack the IS6110 element in their genome using TRC4 primer instead of IS6110 is superior in diagnosing tubercular meningitis by PCR assay.
\end{abstract}

Keywords: Tubercular meningitis, TRC4, IS6110
Volume 7 Issue I - 2019

\author{
Abu Naser Ibne Sattar,' Sanjida Khondakar \\ Setu, ' Md. Towfique Hasan Firoz, ${ }^{2}$ Saleh \\ Mohammad Shahedul Islam ${ }^{3}$ \\ 'Associate Professor, Department of Microbiology \& \\ Immunology, Bangabandhu Sheikh Mujib Medical University, \\ Bangladesh \\ ${ }^{2}$ Assistant Professor, Department of Radiation Oncology, \\ National Institute of cancer Research \& Hospital (NICRH), \\ Bangladesh \\ ${ }^{3}$ Lieutenant Colonel, Medicine Specialist \& Gastroenterologist, \\ Combined Military Hospital, Bangladesh
}

Correspondence: Dr.Abu Naser Ibne Sattar MBBS MD, Associate Professor, Department of Microbiology \& Immunology, Bangabandhu Sheikh Mujib Medical University, Shahbag, Dhaka 1000, Tel +880-01914749527, Email nasersattar@gmail.com

Received: September 10, 2017| Published: January 03, 2019

\section{Introduction}

Tuberculosis (TB) is a highly prevalent global human infection caused by Mycobacterium tuberculosis (MTB). One-third of the world's population is infected with latent TB. Tuberculous meningitis (TBM) can occur as the sole manifestation of TB or concurrent with pulmonary or other extra pulmonary sites of infection. ${ }^{1,2}$ Tuberculosis (TB) is the major cause of death worldwide and is due to a single pathogen. ${ }^{3}$ TB meningitis in particular owes their existence to unsuspected, undiagnosed, or incompletely treated in the community. Mortality due to TB occurs mainly due to the neural form of TB, namely, TB meningitis. Delay in diagnosis and so in the start of effective treatment results in poor prognosis and sequalae in up to $25 \%$ of cases. ${ }^{4}$ Prompt diagnosis is critical for initiating appropriate therapy and facilitating measures to prevent dissemination of this highly contagious disease. The prevalence of TB meningitis remains largely underestimated because clinical manifestations are nonspecific in early stages of the disease and bacteriologic confirmation is available only for a small proportion of patients. Also, clinical diagnosis of TB meningitis is difficult due to its varied clinical presentations. Further, routinely used tests employed for clinical diagnosis of TB are inadequate to detect extrapulmonary forms of TB like TB meningitis. PCR is currently the most sensitive and rapid method to detect extra pulmonary Mycobacterium tuberculosis. ${ }^{5-7}$ We used as a new target TRC4, which was cloned and characterized previously in our laboratory (10). TRC4 is a conserved repetitive element with specificity for M. tuberculosis complex. The aim of this paper was to compare the efficiency of a PCR with a target chosen from this cloned fragment with that of a PCR with the widely used IS6110sequence in detecting M. tuberculosis in cerebrospinal fluid (CSF) samples from patients with meningitis.

\section{Materials and methods}

\section{Study population}

A total of 20 cerebrospinal fluid(CSF) samples collected from clinically suspected cases of tubercular meningitis of all age and sex group which were sent to Microbiology and Immunology Department, Bangabandhu Sheikh Mujib Medical University between March 2013 to February 2014 for laboratory investigation of Mycobacterium tuberculosis, were enrolled in the present study if at least four of the following seven indicators of disease were in evidence: first, the presence of clinical features, such as gradual loss of activity, irritability, clouding of consciousness, convulsions, neck stiffness, and cranial nerve or motor defects; second, contact with an intrafamilial positive for pulmonary TB; third, induration of 10 $\mathrm{mm}$ or more on tuberculin testing with $10 \mathrm{TU}$ of purified protein derivative; and fourth, positive radiological features of primary complex in a chest radiography in the form of hilar lymphadenopathy and/or consolidation with parenchymal infiltrate, segmental collapse, or miliary mottling, or positive cranial imaging computerized axial tomography and magnetic resonance imaging having significant pathological changes for TB meningitis.

All the samples were processed for direct microscopy using conventional ZN staining, TB culture by Lowenstein Jensen (LJ) media and PCR by IS6110 and TRC4 primers. Other supporting investigations were collected from patient case files. Treatment response with anti tuberculour drugs were followed up in all patients in the TB group and showed marked improvement. Out of the 20 patients, 12 were diagnosed as tubercular meningitis and rest were due to other causes based on the diagnostic criteria mentioned below: 
a. Positive tuberculin test and significant level of ADA value $(\geq 10 \mathrm{U} / \mathrm{L}$ ) in lymphocytic exudative fluid (protein level $\geq 80 \mathrm{mg}$ / $\mathrm{dl}$ and /or glucose $\leq 2.5 \mathrm{mmol}$ )

b. Detection of AFB by microscopy or isolation of mycobacteria by culture from clinical samples.

c. Positive tuberculin test and / or high ESR and clear response to anti-TB drugs.

A positive to treatment response was defined as the improvement of clinical and/or imaging findings after two months of treatment. Sample collection and processing Five ml CSF was withdrawn from patients using lumber puncture by attending physician. One $\mathrm{ml}$ was sent for routine biochemical (glucose, protein) test and cytology. Four $\mathrm{ml}$ were used for Gram stain and routine bacteriological culture, L-J culture, ADA, AFB smear for Z-N stain and PCR assay.

\section{PCR assay}

Mycobacterial DNA extraction from the samples were done by Qiagen kit and followed by conventional PCR for the IS6110 and TRC4 gene specific for M.tuberculosis. The eluted DNA can be stored at $-20^{\circ} \mathrm{C}$ until use in PCR. The PCR master mix was prepared according to standard protocol of the kit which contained primer pairs, DNA polymerase, buffer containing dNTPs, $\mathrm{MgCl}_{2}$. This $15 \mu \mathrm{l}$ of master mix is mixed with $5 \mu 1$ of sample's nucleic acid. The needed product was proliferated using primers IS6110 insertion element regions including

\section{5'- CCT GCG AGC GTA GGC GTC GG- 3' \\ 5'- CTC GTC CAG CGC CGC TTC GG-3' and}

using primers TRC4 insertion element regions including

\section{5'-GAC AAC GAC GTG CGC CTA CT-3'}

\section{5'-GAC CGA ATT AGC GTA GCT CC-3'}

The PCR conditions for DNA amplification were an initial denaturation step of $94^{\circ} \mathrm{C}$ for $15 \mathrm{~min}$, followed by 40 cycles of $94^{\circ} \mathrm{C}$ for $5 \mathrm{~min}, 62^{\circ} \mathrm{C}$ for $15 \mathrm{~min}, 72^{\circ} \mathrm{C}$ for $15 \mathrm{~min}$. and a final extension step at $72^{\circ} \mathrm{C}$ for $10 \mathrm{~min}$. The final products assessed by gel electrophoresis were $123 \mathrm{bp}$ for IS6110 and 173bp for TRC4.

\section{Statistical analysis}

After collection all data were checked and edited. Then all data were and analyzed by using computer based SPSS (Statistical Package of Social Science) software version: 21.00 with a $95 \%$ confidence interval $(95 \% \mathrm{CI})$. The results of individual tests were compared by Chi square $\left(\chi^{2}\right)$ test. $\mathrm{p}$ value $<0.05$ was taken as minimum level of significance. Significance was calculated by Z-test of proportion.

\section{Results}

Clinically suspected 20 patients having tubercular meningitis were enrolled in this study. The patients were broadly divided in two groups-tuberculous meningitis patients $(60 \%)$ and non-tuberculous patients $(40 \%)$ group according to the broad case definition in the present study. The mean age of the study subjects was $34.17 \pm 1.42$ years with age ranging from 1-75 years. Out of 20 patients $11(55 \%)$ were males and $9(45 \%)$ were females. The $\mathrm{p}$ value was insignificant suggesting that there was no age and gender bias in selecting the patients for this study. The major presenting clinical features included fever, malaise, weight loss, irritability, convulsion, neck stiffness, clouding of consciousness and anorexia. Out of 12 EPTB cases $7(58.33 \%))$ were tuberculin positive and mean ESR was $87.46 \pm 2.34$. All the 12 TB meningitis patients responded to anti-tuberculous treatment.

Among the twelve TB meningitis cases PCR assay by TRC4 primer showed significantly higher positivity $(\mathrm{p}$ value $<0.05$ ) in 10 $(83.33 \%)$ cases in comparison with PCR assay by IS6110 primer that was positive in $8(66.67 \%)$ and culture that was positive in only one $(8.33 \%)$ cases. None were positive by AFB smear (Table 1 )

Table I Results of AFB smears, mycobacterial culture \& PCR assay among Tubercular meningitis cases $(n=20)$

\begin{tabular}{lll}
\hline Tests & $\begin{array}{c}\text { Number of } \\
\text { positive cases }\end{array}$ & Percentage (\%) \\
\hline AFB smear & $0^{*}$ & 0 \\
Mycobacterial culture & $I^{* *}$ & 8.33 \\
PCR assay by IS6II0 & 8 & 66.67 \\
PCR assay by TRC4 & 10 & 83.33
\end{tabular}

$*_{\mathrm{p}}<0.05$, compared between AFB smear and PCR

** $\mathrm{P}<0.005$, compared between Mycobacterial culture and PCR

We also looked at the agreement between study group by diagnostic criteria and PCR results using two probes (Table 2). Of the 12 diagnostically positive TB meningitis samples, eight were $(66.67 \%)$ positive by PCR using IS6110 probes, whereas ten $(83.33 \%)$ were positive by PCR using TRC4 probes. Of the 8 non-TB samples, $7(87.50 \%)$ were negative by using IS6110 probes, and all were negative by TRC4 probe.

Table 2 Agreement between diagnostic criteria and PCR results using two probes among study population $(\mathrm{n}=20)$

\begin{tabular}{|c|c|c|c|c|}
\hline \multicolumn{5}{|l|}{ PCR primers } \\
\hline & \multicolumn{2}{|c|}{ IS6 I I 0 Primers } & \multicolumn{2}{|c|}{ TRC4 Primers } \\
\hline & Positive & Negative & Positive & Negative \\
\hline TB meningitis $(n=12)$ & 8 & 4 & 10 & 2 \\
\hline Non-TB $(n=8)$ & 1 & 7 & 0 & 8 \\
\hline Total 20 & 9 & II & 10 & 10 \\
\hline
\end{tabular}

\section{Discussion}

Tubercular meningitis diagnosis poses a special challenge as it is often missed or misdiagnosed due to its atypical presentations. Due to the poor performance of conventional microbiological techniques, the diagnosis is largely based on clinical suspicion and nonmicrobiological parameters in CSF specimens. As a result, a number of cases having atypical clinical presentation remain undiagnosed and even worse, untreated and leaves clinician with a long delay without an affirmative answer. In this study, diagnostic efficacy of PCR was evaluated in relation to the conventional techniques. A total of 20 suspected tubercular meningitis cases were included in this study. Among them 12 patients were finally diagnosed as tubercular meningitis and 8 were non-TB cases. Clinical samples collected from this suspected tubercular meningitis cases were subjected to AFB smear, AFB culture and PCR. To assess a better target for PCR amplification, two sets of Mycobacterium tuberculosis complex specific primers, namely IS6110 and TRC4 were used. 
Out of the 12 tuberculor meningitis cases in this study, only $8.33 \%$ were found positive by L-J medium culture. None of the CSF sample were positive by AFB smear examination. This low yield of AFB smear and culture may be due to the paucibacillary nature of EPTB samples. Furthermore, distribution of samples for a number of tests, like cytology, biochemistry, microbiology and PCR, results in inadequate volume and probably unequal distribution of the organism in samples. ${ }^{8}$ The lower positivity of AFB smear and culture in the present study is comparable with that of other study where the positivity of AFB smear and culture was respectively $3 \%$ and $4 \%$ in CSF. ${ }^{9}$ The reason of $\mathrm{AFB}$ smear negativity might be due to the low concentration of mycobacteria in those samples i.e. below the detection limit of 10000 organism $/ \mathrm{ml} .{ }^{10}$ Culture negativity might be explained by the absence of viable mycobacteria in the samples. ${ }^{11}$ Maximum $83.33 \%$ PCR positivity was found in CSF which is comparable with a study in India where CSF sample was found 91\% PCR positive. ${ }^{12}$ All the PCR positive with bacteriological negative cases were responded to antituberculous therapy (ATT) with significant clinical improvement. Cheng et al., ${ }^{11}$ stated that, in patients particularly with clinical and radiological features suggestive of active tuberculosis a negative AFB culture cannot exclude a clinical diagnosis of tuberculosis, as demonstrated in our patients.

Of 8 non-TB samples, a case of meningitis was false positive by PCR assay using IS6110 primer. It can be explained by that, in country like Bangladesh where the prevalence of tuberculosis is very high the possibility of coinfection with tuberculosis may coexist. ${ }^{13}$ This could be also due to cross contamination during tube to tube transfer. ${ }^{14}$ The two samples from patients who were clinically positive and responded to antituberculous therapy were negative by PCR using both probe. This false negativity of PCR test can be explained either by sampling errors (non-uniform distribution of microorganisms), low bacterial load, inefficient extraction of DNA, or the presence of PCR inhibitors. ${ }^{15}$ Monitoring and accurate evaluation of PCR inhibitors is possible only if an internal control is included during DNA amplification which was the main limitation in this study. ${ }^{16}$ In the present study the oligonucleotide primers derived from IS6110, and TRC4 gene, were successfully used to amplify a $123 \mathrm{bp}$ and 173bp DNA sequence in $M$. tuberculosis complex. TRC4 gene-based PCR showed highest $83.33 \%$ positivity and IS6110 showed $66.67 \%$ positivity. As mentioned earlier IS6110 is an excellent target of PCR in detecting $M$ tuberculosis because of its repetitive sequence in the genome. ${ }^{17}$

But in this study four cases of tubercular meningitis were found to be negative by IS6110. These are false negatives because among these four cases one case was positive by bacteriological test and three cases was responded to antituberculous treatment subsequently. Other studies in India and in other geographical regions of the world have also reported similar results. ${ }^{12,18-20}$ Reason of this may be due to absence or low copy number of IS6110 in genome of some isolates of Mycobacterium tuberculosis mostly reported from south-east India, Tanzania, Malaysia, Oman and Denmark. ${ }^{17,21}$ There are no such reports from Bangladesh. But the genotyping analysis of the available oligotype data suggests that IS6110 low copy number strains belong to the $\mathrm{TbDl}+/ \mathrm{EAI}$ lineage, which have recently been reported to be in the range from $25 \%$ to $50 \%$ in Bangladesh and Singapore. ${ }^{22-24}$ PCR assay based on TRC4 primer in this study showed lowest negativity in only two cases among the tubercular meningitis samples. Narayanan et al., ${ }^{25}$ described TRC4 as an insertion like sequence that was present in all M. tuberculosis containing specimens and clinical isolates examined in their laboratory. We found that using primer from a repetitive element like TRC4 can be an ideal target for PCR to identify $M$ tuberculosis from clinical specimens in TB meningitis, especially to detect carrying no copy or single of IS6110 which is comparable to this study. There is limited data available about the performance of 173 bpTRC4 primer based PCR assay in Bangladesh which necessitates its further evaluation. Research also needed to simplify and convert PCR into a cost effective technique that can be set even in an unsophisticated laboratory of a developing country like Bangladesh.

\section{Acknowledgments}

None.

\section{Conflicts of interest}

Authors declare that there is no conflicts of interest.

\section{References}

1. Thwaites G, Fisher M, Hemingway C, et al. British Infection Society guidelines for the diagnosis and treatment of tuberculosis of the central nervous system in adults and children. J Infect. 2009;59(3):167-187.

2. Nelson C, Zunt JR. Tuberculosis of the central nervous system in immunocompromised patients: HIV Infection and solid organ transplant recipients. Clin Infect Dis. 2011;53(9):915-926.

3. Anti-tuberculosis drug resistance in the world. WHO/IUATLD global project on anti-tuberculosis drug resistance surveillance. Geneva, Switzerland: World Health Organization; 1997. 253 p.

4. Garcia-Monco JC. CNS Tuberculosis. Neurol Clin.1999;17(4):737-759.

5. Altamirano MM, Kelly T, Wong A. Characterization of a DNA probe for detection of Mycobacterium tuberculosis complex in clinical samples by polymerase chain reaction. J Clin Microbiol. 1992;30(8):2173-2176.

6. Del Portillo P, Murillo LA, Elkin M. Amplification of a species-specific DNA fragment of Mycobacterium tuberculosis and its possible use in diagnosis. J Clin Microbiol. 1991;29(10):2163-2168.

7. Wilson SM, McNerney R, Nye PM, et al. Progress toward a simplified polymerase chain reaction and its application to diagnosis of tuberculosis. J Clin Microbiol. 1993;31(4):776-782.

8. Chakravorty S, Tyagi JS. Novel multipurpose methodology for detection of Mycobacteria in pulmonary and extra pulmonary specimens by smear microscopy, culture and PCR. J Clin Microbiol. 2005;43(6):2697-2702.

9. Poonam SD, Kashyap, Ramteke SS, et al. Evaluation of the IS6110 PCR assay for the rapid diagnosis of tuberculous meningitis. Cerebrospinal Fluid Res. 2007;4:10.

10. Yeager H Jr, Lacy J, Smith LR, et al. Quantitative studies of mycobacterial population in sputum and saliva. Am Rev Respir Dis. 1967;95(6):9981004.

11. Cheng VCC, Yam WC, Hung IFN, et al. Clinical evaluation of the polymerase chain reaction for the rapid diagnosis of tuberculosis. $J$ Clin Pathol. 2004;57(3):281-285.

12. Narayanan S, Parandaman V, Narayanan PR, et al. Evaluation of PCR using TRC4 and IS6110 Primers in detection of tuberculous meningitis. J Clin Microbiol. 2001;39(5):2006-2008.

13. Chakravorty S, Tyagi JS. Novel multipurpose methodology for detection of Mycobacteria in pulmonary and extra pulmonary specimens by smear microscopy, culture and PCR. J Clin Microbiol. 2005;43(6):2697-2702.

14. Rosso F, Michelon CT, Sperhacke RD et al. Evaluation of real-time PCR of patient pleural effusion for diagnosis of tuberculosis. BMC Res Notes. 2011;4:279. 
15. Singh KK, Muralidhar M, Kumar A, et al. Comparison of in house polymerase chain reaction with conventional techniques forthe detection of Mycobacterium tuberculosis DNA in granulomatous lymphadenopathy. J Clin Pathol. 2000;53(5):355-361.

16. Orallo RLC, Mendoza MT, Ann MD, et al. Evaluation of the Usefulness of PCR in the diagnosis of Mycobacterium tuberculosis in tissues and body fluids in UP-Philippine General Hospital. Philippine J Microbiol Infect Dis. 2008;37(1):20-32.

17. Fumokong NG, Tang TH, Al-Maamry S, et al. Insertion sequence typing of $M$ tuberculosis: Characterization of a widespread sub-type with single copy of IS6110. Tuber Lung Dis. 1994;75(6):435-440.

18. Negi SS, Anand R, Pasha ST, et al. Diagnostic potential of IS6110, $38 \mathrm{KDa}$, and $85 \mathrm{~B}$ sequence based polymerase chain reaction in the diagnosis of Mycobacterium tuberculosis in clinical samples. Indian $J$ Med Microbiol. 2007;25(1):43-49.

19. Thangappah RBP, Paramasivan $\mathrm{CN}$, Sujatha Narayanan S. Evaluating PCR, culture \& histopathology in the diagnosis of female genital tuberculosis. Indian J Med Res. 2011;134:40-46.

20. Barani R, Sarangan G, Antony T, et al. Improved detection of Mycobacterium tuberculosis using two independent PCR targets in a tertiary care centre in South India. J Infect Dev Ctries. 2012;6(1):46-52.
21. Das S, Paramasivan CN, Lewis DB, et al. IS6110 restriction fragment length polymorphism typing of clinical isolates of Mycobacterium tuberculosis from patients with pulmonary tuberculosis in Madras, south India. Tuber Lung Dis.1995;76(6):550-554.

22. Gutierrez MC, Ahmed N, Willery E, et al. Predominance of Ancestral Lineage of Mycobacterium tuberculosis in India. Emerg Infect Dis. 2007;12(9):1367-1374.

23. Shamputa IC, Rigouts L, Eyongeta LA, et al. Genotypic and phenotypic heterogeneity among Mycobacterium tuberculosis isolates from pulmonary tuberculosis patients. J Clin Microbiol. 2004;42(12):552836.

24. Banu S, Gordon SV, Palmer S, et al. Genotypic analysis of Mycobacterium tuberculosis in Bangladesh and prevalence of the Beijing strain. J Clin Microbiol. 2004;42(2):674-682.

25. Narayanan S, Sahadevan R, Narayanan PR. Isolation and characterization of an insertion element-like repetitive sequence specific for Mycobacterium tuberculosis complex. Current science. 1997;73(3):259266. 